\title{
Response Surface Analysis for Acceptability Assessment of Micronutrient Fortified Un-Stabilized Soymilk from Sprouted Soybeans
}

\author{
Okwunodulu IN* and Nwabueze TU \\ Department of Food Science and Technology Michael Okpara University of Agriculture Umudike Abia State, Nigeria \\ *Corresponding Author: Okwunodulu IN, Department of Food Science and Technology, Michael Okpara University of Agriculture \\ Umudike, Abia State Nigeria.
}

Received: August 26, 2019; Published: September 20, 2019

\begin{abstract}
Soymilk is deficient in vitamins and mineral which calls for fortification. Such fortification may affect soymilk appearance, consistency and general acceptability depending on the types and levels of fortimicins used. This study tends to optimize the effect of ferric ammonium citrate, calcium carbonate and vitamin $\mathrm{C}$ on the acceptability of predigested soymilk. Soymilk prepared from $72 \mathrm{~h}$ sprouted TGX 923 - 2E soybean variety after steeping for $12 \mathrm{~h}$ was fortified with ferric ammonium citrate (Fe), calcium carbonate (Ca) and vitamin C (Vit. C) as fortify cant variables according to Box-Wilson (1951) experimental design matrix. Fifteen samples generated were separately subjected to consumer preference test using twenty five semi-trained panelists. A central composite response surface design (CCRSD) for $\mathrm{K}=3$ was employed to study the linear, quadratic and cross product effect of appearance and viscosity (consistency) ratings of the panelists on the general acceptability of the fortified soymilk. Response surface data for each run was regressed and analyzed for variance using Minitab computer software (version 11.21). Results obtained showed that ferric ammonium citrate had significant increase effect on appearance and decrease in general acceptability while calcium carbonate had significant increase in viscosity. Sample with fortification levels of 2, 100 and 32 for ferric ammonium citrate, calcium carbonate and vitamin C respectively had the highest acceptability of 6.74 (Like moderately).

Keywords: Acceptability; Fortified Soymilk; Sprouted Soybean; Response Surface Analysis
\end{abstract}

\section{Introduction}

Soymilk, an aqueous extract of soybean (Glycine max) is endowed with useful essential human nutrients [1,2] and proven evidence of a good substitute for cow`s milk [2]. Soymilk acceptability when fortified with deficient nutrients like vitamins and minerals $[1,3]$ for human consumption $[4,5]$ is best assessed by subjecting it to consumer preference test using a 9 - point Hedonic scale which measures the degree of liking and disliking [6].

Food fortification, a deliberate addition of one or more nutrients to a food whether or not it was normally contained in the food has been adopted as an intervention program for preventing or correcting demonstrated deficiency of one or more nutrients in the population or specific population groups $[7,8]$. Fortification and formulation of foods have been applied in the manufacture of complementary foods from local staples to meet the nutrients and energy needs of infants and young children [9,10]. Besides, varieties of calcium and vitamins B and D fortified beverages have been advanced with the sole aim of providing reasonable percent of their RDI to prevent their deficiency symptoms [11]. Similarly, legume sprouting has been an age long method used by pioneer researchers to increase the nutrient content and bioavailability of essential nutrients, eliminate anti-nutrients and endow soymilk with some health benefits [12]. Sprouting also reduces flatulence [13] and trypsin inhibitor [14,1], and stabilizes soymilk [15].

Response surface methodology (RSM) has been adapted into food process optimization to predict the values of dependent response variables by determining the optimum process variable combinations that maximize or minimize the product response [16]. In this study, RSM was employed to evaluate the magnitude of influence of the process variables (fortify cants) on the response variable (acceptability). The aim of this study is to subjectively optimize the general acceptability of micronutrient fortified un-stabilized soymilk from sprouted soybean.

\section{Material and Methods}

TGX923 - 2E variety of soybean was procured from the National Cereal Research Institute (NCRI) outstation, Amakama Olokoro in Abia State Nigeria.

\section{Preparation of soymilk}

Cleaned whole TGX 923 - 2Esoybean variety, steeped in tap water for $12 \mathrm{~h}$ and drained was sprouted on a cleaned jute sack on the 
floor for $72 \mathrm{~h}$. The beans were sprinkled with water regularly, as soon as their surfaces dry $[12,17]$. The sprouted beans were boiled in $0.5 \% \mathrm{NaHCO}_{3}$ solution for $20 \mathrm{~min}$, drained [13,18], cooled to room temperature $\left(23^{\circ} \mathrm{C}\right.$ to $\left.26^{\circ} \mathrm{C}\right)$ and hand-dehulled. The hulls and the shoots were removed by water floatation to obtain cleaned soybean cotyledons which were milled in Power Deluxe variable speed electric blender (model PDB - 8231 - F) with hot water $\left(93^{\circ} \mathrm{C}\right)$ in a ratio of 2.7 parts hot water to one part cotyledons $(\mathrm{v} / \mathrm{w})$ to form sprouted bean slurry $[3,17]$. Soy extract was obtained by sieving the slurry through a double layered muslin cloth. The oil content of soymilk was evaluated and made up to3.5\% [1]. Soymilk obtained was fortified according to Box-Wilson [19] experimental design matrix (Table 2) and each row in the design matrix was bottled separately as a run and sterilized at $121^{\circ} \mathrm{C}$ for $5 \mathrm{~min}$.

\section{Experimental design and statistical analysis}

Central composite response surface design (CCRSD) for $\mathrm{k}=$ 3 was employed to study the linear, quadratic and interactive effects of the independent experimental variables on general acceptability of micronutrient fortified soymilk from sprouted soybeans. The experimental variables namely ferric ammonium citrate, calcium carbonate and vitamin C were of five levels (Table 1). Box-Wilson [19] experimental design matrix (Table 2) was employed for the fortification. The center point $(0,0,0)$ was only replicated six times [20] for estimation of errors. Analytical determinations were carried out in triplicate on appearance and viscosity. Mean data obtained on each run were regressed and analyzed for variance using Minitab software (version 11.21). Precision of the model was checked using coefficient of determination $\left(\mathrm{R}^{2}\right)$ and correlation coefficient (R) obtained from Minitab software. Statistical significance was acceptable at $5 \%$ probability levels $(\mathrm{P}<0.05)$.

\begin{tabular}{|l|c|c|c|c|c|c|c|}
\hline \multirow{2}{*}{ Independent process variable } & \multirow{2}{*}{ Code } & \multirow{2}{*}{ K=3 } & \multicolumn{5}{|c|}{ Variable levels } \\
\cline { 4 - 8 } & & & $\mathbf{- 1 . 6 8 2}$ & $\mathbf{- 1}$ & $\mathbf{0}$ & $\mathbf{+ 1}$ & $\mathbf{+ 1 . 6 8 2}$ \\
\hline Dietary iron $(\mathrm{mg} / 100 \mathrm{ml})$ & $\mathrm{Fe}$ & $\mathrm{X}_{1}$ & 1 & 2 & 3 & 4 & 5 \\
\hline Calcium $(\mathrm{mg} / 100 \mathrm{ml})$ & $\mathrm{Ca}$ & $\mathrm{X}_{2}$ & 50 & 100 & 150 & 200 & 250 \\
\hline Vitamin C (mg/100ml) & $\mathrm{C}$ & $\mathrm{X}_{3}$ & 8 & 16 & 24 & 32 & 40 \\
\hline
\end{tabular}

Table 1: Five independent process variable combinations used in the design $(k=3)$ Fe $\left(X_{1}\right)=$ ferric ammonium citrate, $C a\left(X_{2}\right)=$ Caicium carbonate, $C\left(X_{3}\right)=$ vitamin $C$.

\begin{tabular}{|c|c|c|c|c|c|c|c|c|c|}
\hline Experimental Runs & \multicolumn{2}{|c|}{ Coded Independent Processes Variables } & \multicolumn{2}{|c|}{ Real Independent Process Variables } & \multicolumn{3}{|c|}{ Responses } \\
\hline & $\mathbf{X}_{\mathbf{1}}$ & $\mathbf{X}_{\mathbf{2}}$ & $\mathbf{X}_{\mathbf{3}}$ & $\mathbf{X}_{\mathbf{1}}$ (Fe) & $\mathbf{X}_{\mathbf{2}}$ (Ca) & $\mathbf{X}_{\mathbf{3}}$ (Vit. C) & $\mathbf{Y}_{\mathbf{1}}$ & $\mathbf{Y}_{\mathbf{2}}$ & $\mathbf{Y}_{\mathbf{3}}$ \\
\hline 1 & -1 & -1 & -1 & 2 & 100 & 16 & 6.71 & 6.88 & 6.59 \\
\hline 2 & -1 & -1 & 1 & 2 & 100 & 32 & 6.60 & 7.00 & 6.61 \\
\hline 3 & -1 & 1 & -1 & 2 & 200 & 16 & 6.30 & 6.32 & 6.65 \\
\hline 4 & -1 & 1 & 1 & 2 & 200 & 32 & 6.21 & 6.41 & 6.74 \\
\hline 5 & 1 & -1 & -1 & 4 & 100 & 16 & 6.11 & 6.61 & 6.25 \\
\hline 6 & 1 & -1 & 1 & 4 & 100 & 32 & 5.92 & 6.70 & 6.12 \\
\hline 7 & 1 & 1 & -1 & 4 & 200 & 16 & 5.91 & 5.95 & 6.21 \\
\hline 8 & 1 & 1 & 1 & 4 & 200 & 32 & 6.00 & 6.04 & 6.25 \\
\hline 9 & 1.682 & 0 & 0 & 5 & 150 & 24 & 5.90 & 5.62 & 5.99 \\
\hline 10 & -1.682 & 0 & 0 & 1 & 150 & 24 & 6.85 & 6.88 & 6.48 \\
\hline 11 & 0 & 1.682 & 0 & 3 & 250 & 24 & 7.11 & 5.91 & 6.08 \\
\hline 12 & 0 & -1.682 & 0 & 3 & 50 & 24 & 5.97 & 6.96 & 6.41 \\
\hline 13 & 0 & 0 & 1.682 & 3 & 150 & 40 & 6.72 & 6.01 & 6.22 \\
\hline 14 & 0 & 0 & -1.682 & 3 & 150 & 8 & 6.80 & 6.18 & 6.10 \\
\hline 15 & 0 & 0 & 0 & 3 & 150 & 24 & 5.91 & 6.13 & 6.29 \\
\hline 0 & 0 & 0 & 0 & 0 & 0 & 0 & 6.89 & 7.01 & 6.48 \\
\hline
\end{tabular}

Table 2: Box-Wilson (1951) experimental design matrix for coded and real independent process variables and their rating responses. $\mathrm{X}_{2}, \mathrm{X}_{3}$ and $\mathrm{X}_{3}$ are the coded values of the respective independent variables. $\mathrm{X}_{1}(\mathrm{Fe}), \mathrm{X}_{2}(\mathrm{Ca})$ and $\mathrm{X}_{3}(\mathrm{VC})$ each represents respective concentrations $(\mathrm{mg} / 100 \mathrm{ml})$ of ferric ammonium citrate, calcium carbonate and vitamin $\mathrm{C}$ fortificants used in the fortification trials. $Y_{1}, Y_{2}$ and $Y_{3}$ each represent respective response on appearance, viscosity and general acceptability. 0 represents unfortified sample. Each row represents the coded variables, real variable values and the ratings of each sample or run. 
Analyses

Sensory evaluation

This was carried out (Table 2) using consumer preference test on fortified samples $(n=15)[21,22]$. Sensory evaluation was carried out at Food Processing Laboratory of Michael Okpara University of Agriculture Umudike, Abia State Nigeria. Twenty five semitrained panelists drowned from student and staff of Food Science and Technology Department of same University aged between 20 to $40 \mathrm{yr}$ were used to rate the samples. Each panelist was presented with 15 coded samples at different times in glass tumblers along with a glass of water. They were to rinse their mouth before and after tasting each sample and score them according to a 9 - point Hedonic Scale, where 1 = dislike extremely, 2 = dislike very much, 3 = dislike moderately, 4 = dislike slightly, $5=$ neither like nor dislike, 6 = like slightly, 7 = like moderately, 8 = like very much, $9=$ like extremely [6]. The parameters rated were appearance, viscosity (consistency) and general acceptability. Data obtained were regressed (Table 3).

\section{Results and Discussion}

Results of sensory scores of the fortified and unfortified soymilk samples were presented in table 2 as $Y_{1}, Y_{2}$ and $Y_{3}$ while those of regression analyses were presented in (Tables 3,4 and 5) respectively for appearance, viscosity and general acceptability.

\begin{tabular}{|l|c|c|c|c|c|c|c|}
\hline Vb. & Coefficient & Linear & Quadratic & $\mathbf{C P}$ & $\mathbf{R}$ & $\mathbf{R}^{\mathbf{2}} \mathbf{( \% )}$ & ANOVA \\
\hline $\mathrm{X}_{1}$ & 0.07162 & $0.004^{*}$ & 0.458 & 0.786 & 0.93 & 87.0 & 0.081 \\
\hline $\mathrm{X}_{2}$ & 0.02465 & 0.138 & 0.994 & 0.885 & NA & NA & 0.081 \\
\hline $\mathrm{X}_{3}$ & -0.00357 & 8.808 & 0.996 & 0.421 & NA & NA & 0.081 \\
\hline
\end{tabular}

Table 3: Regression analysis results showing significant effects $(P \leq 0.05)$ of fortificant variables coded $\left(X_{1}, X_{2}\right.$ and $\left.X_{3}\right)$ on appearance $\left(Y_{1}\right)$. $\mathrm{Vb}=$ variables, $\mathrm{Y}_{1}=$ Appearance, of fortified soymilk. $\mathrm{CP}=$ cross product. $\mathrm{X}_{1} \mathrm{X}_{2}$ and $\mathrm{X}_{3}$ are respective dietary iron, calcium and vitamin $\mathrm{C}$ fortificants, $\mathrm{R}$ is the correlation coefficient and $\mathrm{R}^{2}$ is coefficient of determination. ANOVA is the P-values of themodel.

* indicates significant $(\mathrm{p}<0.05)$ effects, NA indicates no account.

\begin{tabular}{|l|c|c|c|c|c|c|c|}
\hline Vb. & Coefficient & Linear & Quadratic & CP & $\mathbf{R}$ & $\mathbf{R}^{\mathbf{2}} \mathbf{( \% )}$ & ANOVA \\
\hline $\mathrm{X}_{1}$ & -0.05700 & 0.588 & 0.832 & 0.200 & $\mathrm{NA}$ & $\mathrm{NA}$ & 0.197 \\
\hline $\mathrm{X}_{2}$ & 0.26582 & $0.043^{*}$ & 0.267 & 0.179 & 0.89 & 80.0 & 0.197 \\
\hline $\mathrm{X}_{3}$ & 0.5044 & 0.630 & 0.282 & 0.840 & NA & NA & 0.197 \\
\hline
\end{tabular}

Table 4: Regression analysis results showing significant effects $(\mathrm{P} \leq 0.05)$ of fortificant variables coded $\left(\mathrm{X}_{1}, \mathrm{X}_{2}\right.$ and $\left.\mathrm{X}_{3}\right)$ on viscosity $\left(\mathrm{Y}_{2}\right)$. $\mathrm{Vb}=$ variables, $\mathrm{Y}_{2}=$ viscosity of fortified soymilk. $\mathrm{CP}=$ cross product. $\mathrm{X}_{1} \mathrm{X}_{2}$ and $\mathrm{X}_{3}$ are respective dietary iron, calcium and vitamin $\mathrm{C}$ fortificants, $\mathrm{R}$ is the correlation coefficient and $\mathrm{R}^{2}$ is coefficient of determination. ANOVA is the P-values of the model.

$*$ indicates significant $(0<05)$ effect, NA indicates no account.

\begin{tabular}{|l|c|c|c|c|c|c|c|}
\hline Vb. & Coefficient & Linear & Quadratic & CP & $\mathbf{R}$ & $\mathbf{R}^{\mathbf{2}} \mathbf{( \% )}$ & ANOVA \\
\hline $\mathrm{X}_{1}$ & -0.18602 & $0.028^{*}$ & 0.716 & 0.838 & 0.83 & 68.8 & 0.434 \\
\hline $\mathrm{X}_{2}$ & -0.02332 & 0.832 & 0.720 & 0.820 & NA & NA & 0.434 \\
\hline $\mathrm{X}_{3}$ & 0.01306 & 0.671 & 0.645 & 0.885 & NA & NA & 0.434 \\
\hline
\end{tabular}

Table 5: Regression analysis results showing significant effects $(\mathrm{P} \leq 0.05)$ of fortificant variables coded $\left(\mathrm{X}_{1}, \mathrm{X}_{2}\right.$ and $\left.\mathrm{X}_{3}\right)$ on acceptability $\left(\mathrm{Y}_{3}\right)$.

$\mathrm{Vb}=$ variables, $\mathrm{Y}_{3}=$ General acceptability of fortified soymilk. $\mathrm{CP}=$ cross product. $\mathrm{X}_{1} \mathrm{X}_{2}$ and $\mathrm{X}_{3}$ are respective dietary iron, calcium and vitamin $\mathrm{C}$ fortificants, $\mathrm{R}$ is the correlation coefficient and $\mathrm{R}^{2}$ is coefficient of determination. ANOVA is the P-values of the model.* indicates significant $(p<0.05)$ difference, NA indicates no account.

\section{Appearance}

Fortified soymilk appearance showed linear positive significant $(\mathrm{p}<0.05)$ effect (increasing effect) of ferric ammonium citrate $\left(\mathrm{X}_{1}\right)$ which accounted for $87.0 \%$ of total soymilk appearance increase. This increase projected ferric ammonium citrate as a major contributor to soymilk appearance increase. First order is well fitted in this study as ferric ammonium citrate was only significant at linear level. Precision of the model was reflected in the respective $\mathrm{R}$ and $\mathrm{R}^{2}$ values of 0.93 and $87 \%$ with $13 \%$ response variation not explained (Table 3). The ANOVA with $\mathrm{p}$ - value of 0.081 (Table 3) indicated that the model can only predict the cumulative effects of the fortify cants on appearance at $1 \%(p>0.05)$ level. Increase in appearance observed could be due to brown colour of ferric ammonium citrate and concentration used. Dietary iron had been re- 
ported to contribute to off - colour in white food materials like milk and soymilk [7,23]. Despite the off - colour contribution, soymilk acceptability may be traced to vitamin $\mathrm{C}\left(\mathrm{X}_{3}\right)$ inclusion which had been reported to stabilize colour [24]. Besides, Anjum., et al [8] and DSM, [24] have earlier reported that vitamin C $\left(\mathrm{X}_{3}\right)$ improves aesthetic appeal in food products. Also, calcium carbonate had been reported to give soymilk a whiter and less yellow colour [11]. Maximum appearance of 7.11 (Run 11) rating (Table 2) at 3mg/100ml concentration of iron fortify cant was in agreement with the above reports. Calcium carbonate and vitamin $\mathrm{C}$ may have cancelled the off - colour effect of ferric ammonium citrate at $3 \mathrm{mg} / 100 \mathrm{ml}$ level.

\section{Viscosity}

Estimated regression coefficient (Table 3) implicated calcium carbonate $\left(\mathrm{X}_{2}\right)$ with positive linear significant $(\mathrm{P}<0.05)$ effect on apparent viscosity $\left(\mathrm{Y}_{2}\right)$ of soymilk by contributing $80 \%\left(\mathrm{R}^{2}\right)$ of total viscosity increase due to variables and $0.89\left(R^{2}\right)$ which is robust. ANOVA also affirmed the significance $(p>0.05)$ of the model to predict the contribution of the variables at $1 \%$ level. The linear model was selected in this study as $\mathrm{CaCO}_{3}$ was significant at linear level. This linear significant $(\mathrm{p}<0.05)$ viscosity increase may be attributed to concentration of $\mathrm{CaCO}_{3}(\mathrm{X} 2)$, type used, bean variety (STS, 1987) and processing methods adopted $[12,25]$. Hydrolyzed protein due to sprouting and $\mathrm{CaCO}_{3}\left(\mathrm{X}_{2}\right)$ added may have bonded and held soymilk water [26] thereby not only stabilized but also increased the viscosity. Also, hydrolysis of soybean macromolecules by sprouting may have prevented interaction among soymilk components and fortii cants which in turn may have prevents significant viscosity increase that could have affected acceptability. This slight viscosity increase confirmed soymilk component and fortify cant compatibility which portends product stability, consistent and acceptability. Viscosity decides consistency, appearance, quality and stability of soymilk [27]. Knowledge of soymilk viscosity will therefore help for a better understanding of the complex relationship between overall acceptability, soymilk viscosity, and concentration of ingredients [28]. Soy milk viscosity decides acceptability.

\section{General acceptability}

Maximum acceptability rating of 6.74 (Like slightly) was obtained from run 4 (Table 2).Negative linear significant $(\mathrm{p}<0.05)$ effect of ferric ammonium citrate $\left(\mathrm{X}_{1}\right)$ contributed $68.8 \%$ to general acceptability $\left(\mathrm{Y}_{3}\right)$ decrease of the fortified soymilk (Table 3). Ferric ammonium citrate $\left(\mathrm{X}_{1}\right)$ is therefore the primary contributor to this decreasing soymilk acceptability. First order is well adjusted in this study to explain this significant $(p<0.05)$ decreasing effect as a function of ferric ammonium citrate. The model is statistically adequate to explain $68.8 \%$ acceptability variation with coefficient of determination $\left(\mathrm{R}^{2}\right)$ of $68.8 \%$ and $\mathrm{R}$ of 0.83 at $1 \%$ level. The model regression equation on general acceptability is:

$\mathrm{Y}=6.25-0.186 \mathrm{X}_{1}-0.0233 \mathrm{X}_{2}+0.0131 \mathrm{X}_{3}-0.0179 \mathrm{X}_{1}{ }^{*} \mathrm{X}_{2}-0.0304$ $\mathrm{X}_{1}{ }^{*} \mathrm{X}_{3}+0.0217 \mathrm{X}_{2}{ }^{*} \mathrm{X}_{3}+0.0400 \mathrm{X}_{1} \wedge 2+0.0436 \mathrm{X}_{2}^{\wedge} 2+0.0135 \mathrm{X}_{3}^{\wedge} 2$ (1).
On removing the non-significant terms from the regression analysis, the resulting polynomial became: $\mathrm{GA}=6.247-0.186 \mathrm{X}_{1}(2)$.

The ANOVA with p-value of 0.434 (Table 5) showed non-significant $(p>0.05)$ effect of the model to predict the cumulative effects of the fortify cants on general acceptability $\left(\mathrm{Y}_{3}\right)$. This also confirmed model's significant $(p<0.05)$ lack of fit to statistically predict general acceptability as a function of the tested attributes at $5 \%$ confidence level. This indicated that other factors not explained by the model may have increasing effect on acceptability. Addition of stabilizer may have improved general acceptability [11]. Therefore, ferric ammonium citrate $\left(X_{1}\right)$ had an inverse linear relationship with general acceptability $\left(\mathrm{Y}_{3}\right)$ most especially on appearance $\left(Y_{1}\right)$ as reflected in least acceptability (5.99) at highest iron concentration $(5 \mathrm{mg} / 100 \mathrm{ml})$ as shown in Table 2.

Decreasing effect of dietary iron $\left(\mathrm{X}_{1}\right)$ on acceptability $\left(\mathrm{Y}_{3}\right)$ may be traced in part to its deep brown colour as reflected in the strong positive linear significant $(\mathrm{p}<0.05)$ effect on soymilk appearance (Table 5). Lower acceptability recorded (5.99, neither like nor dislike) at higher concentration $(5 \mathrm{mg} / 100 \mathrm{ml})$ of ferric ammonium citrate $\left(\mathrm{X}_{1}\right)$ compared to that (6.48, like slightly) at lower concentration (Table 2) is in line with the reports of Clarke, [7] and Barclay, [23] that dietary iron has lowering effect on acceptability. More so, at highest concentration of $\mathrm{CaCO}_{3}$ in run 11 (Table 2), appearance was scored 7.11, consistency was scored least (5.91), and general acceptability $\left(\mathrm{Y}_{3}\right)$ was scored second to the least (6.08, like slightly). These results could be traced to absence of stabilizer which works best with calcium fortification [7] and agreed with the report of SMI, [11] that $\mathrm{CaCO}_{3}$ had an inverse relationship with consistency and acceptability unless stabilized. Choice of $\mathrm{CaCO}_{3}\left(\mathrm{X}_{2}\right)$ which is less reactive with food matrix and a high level fortify cant that delivers the required level of calcium in fortified soymilk with small amount to leave soymilk with desirable mouth feel and clarity [11] may have improved acceptability Anjum., et al. [8] and DSM, [24] had earlier reported that vitamin C improves aesthetic appeal in food products. Positive coefficient of vitamin $\mathrm{C}$ in this study indicated slight ability to increase general acceptability probably due to its antioxidant property [24]. Earlier reports have confirmed that vitamin $\mathrm{C}$ protects oxidation of fats and oil, improves the stability of other added nutrients, aids in dietary iron absorption $[7,24]$ and increases acceptability.

Ranking of soymilk attributes by the panelists despite absence of stabilizer observed in this study which fell between like slightly and like moderately according to 9 - point Hedonic scale may be ascribed in part to choice of fortify cants, combinations used, and the unit operations employed. Sorting of broken beans eliminates rancid flavour and undesirable appearance [29]. Bean steeping prior to sprouting removes off-flavour associated with un-steeped beans [30]. Sprouting which had been reported by Nsofor and Madukor, [17] to hydrolyze soybean oligosaccharides must have contributed to palatability of the soymilk due to increased glucose and fructose. Various heat treatments during bicarbonate blanching, hot grinding and boiling of extracts may have eliminated some enzymes responsible for off - flavour and acid forming bacteria re- 
sponsible for spoilage [1,3]. Also dehulling may have removed offflavour [31] associated with soymilk from underholed beans. The choice of using unsaturated soybean oil in the fortification may have contributed to the desirable flavour and good mouth feel [3] thereby increased acceptability. Also, choice and concentrations of the chemically micronized insoluble iron salt (ferric ammonium citrate) used in this study must have reduced sensory problems due to soluble iron [32]. These acceptability enhancement notwithstanding, the ratings could have been higher than what was obtained if soymilk had been adequately and appropriately stabilized and homogenized [11,32].

\section{Conclusion}

General acceptability of vitamin and mineral fortified soymilk which rated between liked slightly and moderately in this study depended on the types and levels of fortify cants used. Ferric ammonium citrate and calcium carbonate had linear increasing effects on the fortified soymilk appearance but ferric ammonium citrate was more significant $(p<0.05)$. Both in turn decreased acceptability slightly. Calcium carbonate had linear significant ( $p<$ 0.05 ) increasing effect on viscosity (consistency) of the fortified soymilk while vitamin $\mathrm{C}$ had non-significant $(\mathrm{p}>0.05)$ increasing effect. Only ferric ammonium citrate had non-significant decreasing effect. Significant $(p<0.05)$ linear decreasing effect of ferric ammonium citrate on acceptability along non-significant $(p>0.05)$ decreasing effect of calcium carbonate may have over shadowed the increasing effect of vitamin $\mathrm{C}$ to reduce the acceptability. Maximum acceptability level of 6.74 obtained in fortify cant combination of 2: 200:32 for ferric ammonium citrate, calcium carbonate and vitamin $\mathrm{C}$ had lower iron content. Therefore, choice and concentration of ferric ammonium citrate should be visited with caution. General acceptability of the fortified soymilk could have been higher if the viscosity had been increased through stabilization.

\section{Acknowledgement}

The authors are grateful to National Cereal Research Institute (NCRI) outstation, Amakama Olokoro for supply of soybeans and Department of Food Science and Technology both in Abia State, Nigeria for research space. Our special regards goes to World Bank Assisted Step B Project for their financial assistance.

\section{Bibliography}

1. Iwe MO. "The Science and Technology of Soybean". Published by Rojoint Communication Services Ltd (2003): 27-262.

2. Onyibe JE., et al. Production and Quality Evaluation of Probiotic Soy milk". Nigerian Food Journal 27.1(2009): 66-74.

3. Soya Technology Systems Ltd (STS). Soymilk in Brief - A Case that Makes Scence 11. DhobyGhaut. No.11-06 Gathay Building Singapore 0922 (1987) 9-47.

4. Iwe MO. "Principles of Complementary Foods Formulation". An Invited Paper Presented at the Zonal Consultation on Breast Feeding and Complementary Feeding Held at the Marble Arch Hotel, Awka Anambra State (2010).
5. World Health Organization (WHO) (2010).

6. Ihekoronye AI And Ngoddy PO. "Integrated Food Science and Technology for the Tropics". Published by Macmillan Education Ltd London and Oxford (1985): 165-193.

7. Clarke RI. "Micronutirient Fortification of Foods: Technology and Quality Control". FAO Corporate Document Repository (1995).

8. Anjum FM., et al. "Use of Iron as Fortifi cant in Whole Wheat Flour and in Leavened Flat Breads in Developing Countries (a review)". Electronic Journal of Environmental Agriculture and Food Chemistry (2006):1366-1370.

9. Chessa KL and Kathryn GD. "Proposed nutrient composition for fortified complementary foods". The American Society for Nutritional Sciences 133.9 (2003): 11-20.

10. Mosha TC And Vicent MM. "Nutritional Value and Acceptability of Home made Maize-sorghum-based Weaning Mixtures Complemented with Rojo bean Flour, Ground Sardines and Peanut paste". International Journal of Food Sciences and Nutrition 55.4 (2004): 301-315.

11. Specialty Mineral Incorporated (SMI) Interactions of precipitated calcium carbonate (PCC) with proteins in the calcium fortification of dairy and non-dairy beverages (2009).

12. Mostafa MM., et al. "Chemical and Nutritional Changes in Soybeans during Germination". Food Chemistry 23.4 (1987): $257-$ 275 .

13. Omosaiye 0., et al. "Removal of Oligosaccharides from Soybean Water Extracts by Ultrafiltration". Journal of Food Science 43 (1978): 353-360.

14. Wassef EA., et al. "Protease Digestion of the Meals of Ungerminated Soya Beans". Journal of the Science of Food and Agriculture 44.3 (1988):201-214.

15. Osuji CM and Ubbaonu CN. "Chemical and Physical Properties of Predigested Soymilk Concentrates Developed by Enzyme Hydrolysis of Soybean Extracts. Nutritional Society of Nigeria 34th Annual Conference and Scientific Meeting. Theme: Child Survival and the Right of Adequate Nutrition. 2004". York San Francisco London (2004): 219 - 246.

16. Safe-Dedeh S and Saalia FK. "Extrusion of Maize-cowpea Blends in a Modified Oil Expeller". Journal of the Science of Food and Agriculture 73 (1997): 160-168.

17. Nsofor LM And Maduako 0. "Stabilized Soymilk for Ambient Tropical Storage: A Preliminary Report". International Journal of Food Science and Technology 27.5 (1992): 573-576.

18. Bankhead RR. "Effects of Sodium Bicarbonate Blanch on the Retention of Micro-Nutrients in Soy Beverage". Journal of Food Science 43.2 (1978): 345-348. 
19. Box GEP and Wilson KB. "On the Experimental Attainment of Optimun Conditions”. Jason Roy stats 13.1 (1951): 1-45.

20. Iwe MO., et al. "Behavior of Gelatinization and Viscosity in Soy-sweet Potato Mixtures by Single Screw Extrusion: A Response Surface Analysis". Journal of Food Engineering 38.3 (1998): 369-379.

21. Iwe MO. "Current Trends in Sensory Evaluation of Food". Published by Rojoint Communication Services Ltd (2007):106137.

22. Chougrani F., et al. "Physico-Chemical and Rheological Properties of Yoghurt Manufactured with Ewe's Milk and Skim Milk". African Journal of Biotech 8.9 (2009):1938-1942.

23. Barclay D. "Multiple Fortification of Beverages" (2011).

24. Dutch State Mines (DSM) DSM Nutritional Products' Vitamin C - Our Portfolio of Vitamin C Products. Copyright DSM Nutritional Products (2011).

25. Nsofor LM And Osuji CM. "Stability, Rheology and Chemical Properties of Soymilk Concentrate Developed from Sprouted Soybeans". Journal of Food Science and Technology 34 (1997): 33-40.

26. Igyor MA., et al. "Functional and Sensory Properties of Fermented Fura Powder Supplemented with Soy". Nigerian Food Journal 29(2011): 113-121.

27. Food Science and Technology Abstract (FSTA). Quest for Quality goes Full Throttle, FSTA Report (2009).

28. Rao MA. "Shear Rheology of Liquid Foods". Encyclopedia of Agriculture, Food and Biological Engineering Abstract (2003).

29. Onweluzo JC and Nwakalor C. "Development and Evaluation of Vegetable Milk from Treculia Africana (Decne) Seeds". Pakistan Journal of Nutrition 8.3 (2009): 233-238.

30. Youssef MM., et al. "Effects of Dehulling, Soaking and Germination on Chemical Composition, Mineral Elements and Protein Patterns of Faba Beans (ViciaFaba L.)". Food Chemistry 23.2 (1987): 129-138.

31. Mellor N., et al. "Reduction of Off-Flavour Generation in Soybean Homogenates; A Mathematical Model". Journal of Food Science 75.7 (2010): R131-R138.

32. MI (Mineral Incorporated). Properties of Minerals Used in Cereal Foritifcation (Sectionin 6 in MI's Foritifcation Handbook (2011).

\section{Volume 3 Issue 10 October 2019}

(C) All rights are reserved by Okwunodulu IN and Nwabueze TU. 